\title{
Effect of eggshell powder application on the shear bond strength of bulk-fill resin composite to bleached enamel
}

\author{
Lamiaa M. Moharam * ${ }^{*}$ and Shahinaz N. Hassan
}

\begin{abstract}
Objective: To investigate experimental eggshell powder (ESP) solution application effect on shear bond strength (SBS) test timing of bulk-fill resin composite to bleached enamel.

Methods: Eighty bovine-extracted anterior teeth were alienated to eight groups $(n=10)$, representing shear bond strength test timing periods (immediate or delayed) and the remineralizing agents investigated (MI paste Plus and ESP solution). Enamel surfaces were bleached using in-office chemical bleaching agent and the two remineralizing agents were applied then self-etch adhesive and bulk-fill resin composite were performed at $24 \mathrm{~h}$ and $14 \mathrm{~d}$ before SBS test was done. One-way ANOVA followed by Tukey post hoc test was performed for statistical analysis.

Results: The control groups showed the highest mean values, while the bleached enamel groups recorded the least mean values. ESP bleached enamel group recorded a significantly higher mean SBS values than MI paste Plus bleached group. Delayed SBS groups showed higher mean values than immediate SBS groups except for control group.
\end{abstract}

Conclusions: ESP had a positive and significant effect on SBS of bulk-fill resin composite to bleached enamel surface. Delaying the bonding procedure and restoration of the bleached teeth using resin composite restorations results in a better bond durability.

Keywords: Eggshell powder, Shear bond strength, Bulk-fill resin composite, Bleached enamel

\section{Background}

Teeth bleaching has been playing a major role in cosmetic dentistry in the recent years. It represents one of the main patient's desires seeking a beautiful smile. Teeth bleaching had been proven to be safe, cost-effective as well as the most conservative method (Dutra et al. 2017). It has been considered the first choice for treating discolored teeth. However, sometimes it had to be used in conjunction with resin composites to achieve more esthetic results (Borges et al 2007). Nonetheless, a reduced resin composite immediate bond strength to

*Correspondence: lamia.moharam@gmail.com

Restorative and Dental Materials Department, National Research Centre, El-Bohouth Street, Dokki, Cairo, Egypt bleached enamel was reported (Cheng et al. 2019). Such reduction became an essential concern in the esthetic dentistry regarding the clinical applications involving resin bonding (Chuang et al. 2009). It has been stated that application of remineralizing agents later to bleaching procedures might affect the resin bonding to tooth structure and might reduce the post bleaching procedure adverse effects (Kharosthi and Ghazalgoo 2013). Therefore, several studies were published to understand the effect of remineralizing agents on early enamel carious lesions following bleaching procedures to reduce post bleaching side effects (Feroz et al. 2017).

Chicken eggshell powder (CESP) has been investigated in different fields of dentistry for its potential use. Eggshell is known to be a rich source of calcium, and it 
contains many other beneficial elements. It has been stated to be biocompatible and safe alternative for bone defects regeneration. It was reported that eggshell could be used as a remineralizing agent in the form of a solution as its constituents' mineral ions could diffuse into the superficial enamel surface causing obstruction to the surface porosities (Haghgoo et al. 2016).

Therefore, the present in vitro study was conducted to assess the application influence of eggshell solution on the immediate and delayed shear bond strength of a bulkfill resin composite restoration to bleached enamel.

The null hypothesis was that the prepared eggshell powder solution had no significant effect on either immediate or delayed resin composite shear bond strength to bleached enamel surface.

\section{Methods}

\section{Selected materials}

The tested materials brand name, description, composition, and their manufacturers are recorded in Table 1.

\section{Study design}

A total of 80 bovine anterior extracted teeth were alienated to eight groups $(n=10)$, representing timing of shear bond strength testing (immediate/after $24 \mathrm{~h}$ and delayed/ after $14 \mathrm{~d}$ ) and the remineralizing agents investigated in the study (MI paste Plus and ESP solution) as follows:

Group A; Immediate SBS no bleaching (control). Group B; Immediate SBS after bleaching.

Group C; Immediate SBS after bleaching + MI paste Plus.
Group D; Immediate SBS after bleaching +ESP solution.

Group E; Delayed SBS no bleaching (control).

Group F; Delayed SBS after bleaching.

Group G; Delayed SBS after bleaching + MI paste Plus.

Group H; Delayed SBS after bleaching +ESP solution.

\section{Teeth selection and preparation}

Eighty anterior bovine teeth were selected then scraped manually using scaler and under running tap water were washed to ensure complete removal of any residual debris or tissues. The teeth had their roots cut at the cementumenamel junction with a double side-cutting diamond disc mounted at a low-speed hand piece. Pulpal tissues were removed with barded-broach then pink wax was used to seal the pulpal chambers. Silicon carbide abrasive papers of $1000-1200$ grits were used under wet condition to have a standardized enamel flat surface.

\section{Production of eggshell powder (ESP)}

Calcination process was used to produce the ESP according to the protocol proposed by the World Property intellectual organization (WO/2004/105912: Eggshell powder production method: Methods of producing eggshell powder: Patents: US 20060062857 A1). Such process was performed to produce a pathogen-free pure powder of an increased alkalinity. The shells of 20 chicken eggs were cleaned using distilled water. The eggshells were then kept in a hot water bath at $100^{\circ} \mathrm{C}$ for $10 \mathrm{~min}$ followed by

Table 1 Investigated materials, description, ingredients, and manufacturer

\begin{tabular}{|c|c|c|c|}
\hline Material & Description & Composition & Manufacturer \\
\hline GC MI Paste Plus & $\begin{array}{l}\text { Topical Tooth Crème with Milk Casein } \\
\text { \& Bio-available Calcium, Phosphate \& } \\
\text { Fluoride }\end{array}$ & $\begin{array}{l}\text { Pure water, d-sorbitol, NaF 0.20\% w/w } \\
\text { (900 ppm F), Glycerol 10-20\%, Phosphoric } \\
\text { acid, Sodium carboxyl methyl cellulose } \\
\text { (CMC-Na) 1-5\%, Propane-1,2-diol 1-5\%, } \\
\text { Silicon dioxide, Titanium dioxide 1-5\%, } \\
\text { Xylitol, CPP-ACP, propylene glycol, Sodium } \\
\text { saccharin, Ethyl p-hydroxybenzoate, Pro- } \\
\text { pyl p-hydroxybenzoate, Butyl p-hydroxy- } \\
\text { benzoate, Melon flavor }\end{array}$ & GC America Inc., IL, USA \\
\hline $\begin{array}{l}\text { WHITESmile POWER } \\
\text { WHITENING 40\% } \\
\text { YF gel }\end{array}$ & $\begin{array}{l}\text { In-Office, chemically activated teeth } \\
\text { whitening system }\end{array}$ & $\begin{array}{l}\text { 40\% Hydrogen peroxide (32\% mixed). } \\
\text { 3-aminopropyldiethylamine, N, N-diethyl- } \\
\text { 1,3-diaminopropane (<1\%), Flavor }\end{array}$ & WHITEsmile GmbH, Birkenau, Germany \\
\hline Futurabond U & Dual-cured self-etch adhesive & $\begin{array}{l}\text { Liquid 1: Camphorquinone, BHT, dimeth- } \\
\text { acrylates, amine, fumed silica, acid-modi- } \\
\text { fied methacrylates } \\
\text { Liquid 2: DC catalyst, water, ethanol }\end{array}$ & VOCO GmbH, Cuxhaven, Germany \\
\hline X-tra fil & Bulk-fill hybrid resin composite & 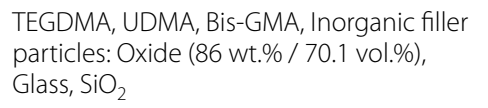 & VOCO GmbH, Cuxhaven, Germany \\
\hline
\end{tabular}

TEGDMA triethylene glycol dimethacrylate, UDMA urethane dimethacrylate, Bis-GMA bis-phenol-a glycidyl-methacrylate 
membrane removal of the shells. Using a sterile mortar and pestle, the eggshells were crushed then heated at $1200^{\circ} \mathrm{C}$ in an oven and finally powdered into small-sized particles.

\section{Production of ESP solution}

One gram of ESP was liquified in $20 \mathrm{ml}$ of $4 \%$ acetic acid (PioChem, Giza, Egypt) and then the clear solution formed at the top was collected and its $\mathrm{pH}$ was 12 (Shen et al. 2011).

\section{Teeth bleaching procedures}

The crowns of the prepared specimens were arranged on a clean dry glass slab. White smile chemical-activated bleaching gel was dispensed from the dual barrel syringe and the bleaching gel was applied to the entire labial surfaces of each tooth in a $1.5-2 \mathrm{~mm}$ thick layer. The gel was left undisturbed on the teeth surfaces for $15 \mathrm{~min}$. Afterward, the bleaching gel was removed from the surfaces of the specimens using a dry piece of cotton. This procedure was repeated for three times to ensure a 45 min treatment of the bleaching agent.

\section{Application of the remineralizing agents}

GC MI paste Plus application, the assigned groups of the bleached specimens were subjected to GC MI paste Plus remineralizing agent application. The paste was applied using an application swap in a generous amount to the labial surfaces of the bleached specimens and left undisturbed for $30 \mathrm{~min}$. Then, the cream had to be removed from the teeth surfaces with cotton rolls and rinsed with distilled water.

ESP solution application; the assigned groups of the bleached specimens were subjected to application of the experimentally prepared ESP solution. The solution was applied to the entire labial surfaces of the bleached specimens using small micro-brushes and the solution was left undisturbed for $30 \mathrm{~min}$. The solution was then removed using cotton rolls from all teeth surfaces then rinsed with distilled water.

\section{Adhesive system and bulk-fill resin composite application}

The treated specimens were fixed using a small piece of double-side adhesive tape in cupper molds $(10 \mathrm{~mm}$ height $\times 30 \mathrm{~mm}$ length $\times 20 \mathrm{~mm}$ width). The labial surfaces of the treated specimens were directed downward. Then the teeth were mounted in self-cure acrylic resin (Acrostone, Acrostone Dental Factory, Egypt). After complete setting of the acrylic blocks, Futurabond $U$ single dose self-etch universal adhesive blisters was activated according to the manufacturers instruction by blister pressing so that the dispensing chamber would be filled with the liquid. Using a single Tim applicator to apply 2 to 3 coats of the universal adhesive system, each blister foil was pricked, and a meticulous mixing of the adhesive was done for $2 \mathrm{~s}$ to reach a consistent mix. Afterward, the enamel surfaces were treated with the adhesive that was softly brushed over the enamel surfaces for $20 \mathrm{~s}$ followed by $5 \mathrm{~s}$ of gentle air-drying to adjust the film thickness and consistency. LED light-curing unit (Elipar S10, 3 M ESPE, USA) was equipped to light cure the adhesive layer for $10 \mathrm{~s}$. LED curing unit had an intensity $\geq 1000 \mathrm{~mW} / \mathrm{cm}^{2}$. The LED curing device intensity was sporadically checked with portable radiometer (Demetron 100, Kerr Corporation, Orange, CA, USA).

Clear plastic tubes $(2 \mathrm{~mm}$ diameter $\times 2 \mathrm{~mm}$ height $)$ were placed at the cervical $1 / 3$ of the labial surfaces of the prepared crowns of the treated specimens and then $\mathrm{X}$-tra fil bulk-fill resin composite was packed inside each tube in one increment then a polyester strip and a glass slide were placed over the top surface of the resin composite and gently pressed. Light curing of the resin composite for $10 \mathrm{~s}$ was done as recommended by the manufacturers. The plastic tubes were carefully cut using sharp blade and the flashes of resin composite and adhesive extending beyond the base of each resin composite disc were carefully removed with the sharp blade. Prepared specimens were kept at $37{ }^{\circ} \mathrm{C}$ in tightseal vessels till SBS testing.

\section{Shear bond strength testing (SBS)}

The acrylic-mounted specimens were attached to the lower jig of the universal testing machine (Shimadzu 5 KN, Autograph AG_X Plus, Japan) and a chisel-bladed metallic attachment was attached to the upper jig of the universal testing machine. Then, the chisel was carefully positioned as close as possible to resin composite/enamel interface. SBS test was run at $0.5 \mathrm{~mm} / \mathrm{min}$ cross head speed up until failure. The maximum force is calculated in $\mathrm{MPa}$.

\section{Statistical analysis}

Standard deviation and mean values were calculated for each group. Using Kolmogorov-Smirnov and ShapiroWilk tests; the given data were inspected for normality and it showed a parametric (normal) distribution. Tukey post hoc test preceded by One-way ANOVA was used to compare between more than two tested groups in non-related samples. Paired sample $t$ test was utilized for comparison between two tested groups within related samples. IBM ${ }^{\circledR}$ SPSS $^{\circledR}$ Statistics Version 20 for Windows was equipped for the statistical analysis, and $P \leq 0.05$ was set as the significance level. 


\section{Results}

Table 2 showed One-way ANOVA results of the immediate and delayed SBS to bleached enamel following the two tested remineralizing agents (MI paste Plus and ESP solution) application. Regarding immediate SBS testing (SBS after $24 \mathrm{~h}$ ); groups $\mathbf{A}, \mathbf{B}, \mathbf{C}$ and $\mathbf{D}$ showed a statistically significant difference at $(p<0.001)$. At $(p<0.001)$, a statistical significantly difference was found between group $\mathbf{A}$ and each of $\mathbf{B}, \mathbf{C}$ and $\mathbf{D}$ groups. Group A $(23.89 \pm 0.51)$ had the highest mean value, while the least mean value was recorded for group B $(7.33 \pm 0.34)$. On the other hand, a statistical significantly difference was found between group $\mathbf{C}$ and $\mathbf{D}$. Group D $(11.67 \pm 0.58)$ recorded a higher mean value than group $\mathbf{C}(9.44 \pm 0.84)$.

Concerning the delayed shear bond strength testing (SBS after 14 d) results; A, B, C and D groups had a statistical significantly difference between them. A statistical significantly difference was found between group $\mathbf{B}$ and each of $\mathbf{A}$ and $\mathbf{D}$ groups. Nevertheless, there was no statistical significantly difference between any other groups. Group A $(23.89 \pm 0.51)$ had the highest mean value while the least mean value was recorded for group B (19.33 \pm 1.21$)$. Moreover, Group D $(23.67 \pm 1.15)$ recorded a higher mean value than group C $(21.44 \pm 1.02)$. For the effect of SBS test timing regardless of the application of the two tested remineralizing agents; $\mathbf{B}, \mathbf{C}$ and $\mathbf{D}$ groups showed a statistically significant difference between (immediate SBS/ $24 \mathrm{~h}$ ) and (delayed SBS/14 d) groups.

Table 2 Standard deviation (SD) and mean values of SBS for different groups

\begin{tabular}{|c|c|c|c|c|c|}
\hline \multirow[t]{3}{*}{ Groups } & \multicolumn{4}{|c|}{ Shear bond strength (SBS) } & \multirow[t]{3}{*}{$p$-value } \\
\hline & \multicolumn{2}{|c|}{$\begin{array}{l}\text { Immediate: } \\
\text { after } 24 \mathrm{~h}\end{array}$} & \multicolumn{2}{|c|}{$\begin{array}{l}\text { Delayed: after } \\
14 \mathrm{~d}\end{array}$} & \\
\hline & Mean & SD & Mean & SD & \\
\hline Control & $23.89^{\mathrm{aA}}$ & 0.51 & $23.89^{\mathrm{aA}}$ & 0.51 & $1 \mathrm{~ns}$ \\
\hline Bleached enamel & $7.33 \mathrm{~dB}$ & 0.34 & $19.33^{\mathrm{bA}}$ & 1.21 & $0.002^{*}$ \\
\hline $\begin{array}{l}\text { Bleached enamel + MI paste } \\
\text { Plus }\end{array}$ & $9.44^{C B}$ & 0.84 & $21.44^{\mathrm{abA}}$ & 1.02 & $0.005^{*}$ \\
\hline $\begin{array}{l}\text { Bleached enamel + ESP } \\
\text { solution }\end{array}$ & $11.67^{\mathrm{bB}}$ & 0.58 & $23.67^{\mathrm{aA}}$ & 1.15 & $0.002^{*}$ \\
\hline$p$-value & $<0.001^{*}$ & & $0.002 *$ & & \\
\hline
\end{tabular}

Mean values with the same capital letters at the same row reveal non-significant difference

Mean values with the same small letters at the same column reveal nonsignificant difference

ns; non-significant $(p>0.05)$, * significant $(p<0.05)$

\section{Discussion}

Bleaching vital teeth has been considered one of the most effective methods to manage discolored teeth. It has been admitted as a conservative approach to gain esthetic effects rather than gaining any other treatment (Attia and Kamel 2019).

Several studies reported the benefits of using remineralizing agents next to bleaching procedures to reduce the post bleaching side effects. These studies used eggshell powder in the form of a solution as a remineralizing agent to aid in remineralization of the enamel surface. It has been noted that following its application, the mineral ions could diffuse into the enamel superficial layer obstructing the enamel surface porosities (Feroz et al. 2017 and Haghgoo et al. 2016).

The null hypothesis was rejected as the tested ESP solution had a significant effect on both immediate and delayed SBS of the bulk-fill composite restoration to the surface of bleached enamel. The current study is the one of the earliest studies to investigate the effect of ESP on bonding to bleached enamel; thus, no literature was available for comparison with the results of our study.

The results of the current study revealed a statistically significant difference in the mean SBS value between all groups after $24 \mathrm{~h}$ (Immediate) and after $14 \mathrm{~d}$ (Delayed). The control group represented the highest mean SBS after both timings. The bleached enamel group represented lower mean SBS value compared to the control group after both $24 \mathrm{~h}$ and $14 \mathrm{~d}$. This could be owed to the reduction in the enamel mineral content and reduction in the enamel prisms which occurs following the application of the bleaching agents to enamel surface (Dishman et al. 1994).

Furthermore, the poor quality of the enamel after bleaching procedures might have prevented the proper micromechanical interlocking between the adhesive/ composite system and the bleached enamel surface (Mobarak et al. 2015).

It was documented that a significant reduction has occurred in the SBS when performing the bonding procedures on the surface enamel immediately following bleaching procedures (Vidhya et al. 2011). Such reduction could be attributed to the breakdown of hydrogen peroxide that caused the release of the free radicals in addition to alterations that occurred on the enamel structure and composition. The presence of that residual oxygen in the interprismatic spaces could impede and inhibits the polymerization and interferes with the resin infiltration (Guler et al. 2013).

Moosavi et al. (2015) and Cheng et al. (2019) agreed to our study. They stated that bleaching procedures caused a significant reduction on the SBS of the resin composites. Likewise, they added that the bond strength of the 
restorations with the surface enamel could be affected with the peroxide concentrations.

Additionally, there was an increase in the mean SBS value of the bleached enamel group after $14 \mathrm{~d}$ (Delayed) compared to bleached enamel group after $24 \mathrm{~h}$ (Immediate). Such results indicate that more time is required to reduce or eliminate the effect of bleaching procedures on SBS values. This might be owed to the increased levels of residual oxygen generated that were accumulated in the bleached tooth surface (Torneck et al. 1991). This residual oxygen might have been leached out more significantly during the $2 \mathrm{w}$ period leading to a decrease or even complete elimination of the inhibition of the resin polymerization and consequently higher SBS values.

Bulucu and Ozsezer 2007 were in accordance with our results. They reported that the specimens bonded 14 $\mathrm{d}$ after bleaching showed higher SBS mean values compared to those bonded after one week. They attributed their results to increasing the time needed to clear out the bleaching adverse effect on the SBS.

On the other hand, White et al. 2008 were in a contradiction with our study. They stated that performing bonding procedures $14 \mathrm{~d}$ following bleaching treatments using different peroxide concentrations had no influence on the bond strength of the resin composite. They owed their diverge results to the type of tested materials, whether the bleaching agents or the composite/adhesive system.

It was concluded previously that performing bonding procedures should not be carried out immediately after bleaching treatment and there should be a waiting period from one to three weeks to perform them (Cura et al. 2015; Yu et al. 2015) to overcome the draw backs of the bleaching procedure (Dishman et al. 1994). Since the etched enamel has a high surface energy then the oxidation reaction produced from bleaching might reduce that increased surface energy and might affect the wettability of the surface substrate by the action of hydrophobic bonding agents. That reduction in the SBS immediately after bleaching might be attributed to the chemical change on the surface enamel that might interfere with the acid-etch technique (Torneck et al. 1990).

Other studies found that the SBS could be improved if there is a waiting period after bleaching to start proceeding for a restoration placement (Hussain and Wang 2010 and Lago et al. 2013). Shinahara et al. 2004 and Van der Vyver et al. 1997 stated that two weeks are the best time to start restoring the tooth structure after performing bleaching procedure to improve the bond strength between the resin composite and the enamel surface.

The results of that study showed that there was increased mean immediate and delayed SBS values in both bleached enamel groups followed by the application of MI paste Plus and ESP solution compared to the bleached enamel groups. This might be due to the application of remineralizing agents following bleaching procedures, which might have reduced bleaching drawbacks through alteration of the chemistry of the bleached tooth surface. These results were in an agreement with Mobarak et al. 2015. The authors tested the influence of using remineralizing agents on the bond strength of resin composite. They reported that remineralizing agents could regain the enamel bonding to a comparable level in comparison to sound enamel.

MI paste Plus consists of (CCP-ACP) casein phosphopeptide-amorphous calcium phosphate plus sodium fluoride. CCP-ACP has been found to be superior in reducing the caries risk. In addition, it stabilizes the calcium and phosphate ions and serves as reservoir of small clusters to enhance remineralization and control demineralization. Moreover, the presence of the fluoride within the CCP-ACP could enhance fluorapatite formation. Moreover, it was reported that ACP can produce a layer of hydroxyapatite on enamel surface (Moule et al. 2007) and it might have a re-hardening influence on tooth structures as well. Khoroushi and Ghazalgoo 2013 stated that application of remineralizing agents following bleaching procedures could influence the bond strength between the resin composite and the tooth structure. Furthermore, it was assumed that the enamel surface regains its hardness when the remineralizing agent was applied after bleaching treatment (Kutuk et al. 2018).

CESP is regarded as the best natural source of calcium. The increased $\mathrm{pH}$ of CESP might have increased the activity of the phosphate and hydroxyl ions present in the solution. Hereafter, the remineralization will be much improved (Mony et al. 2015). It was stated that eggshell solutions could be used as a remineralizing agent as well as an adjunct to nano-hydroxyapatite and fluoride since it is a rich source of calcium, phosphorus, and many other elements (Haghgoo et al. 2016). The results of the current study revealed increased SBS values in the (Bleached enamel and ESP solution) group compared to (Bleached enamel and MI paste Plus) group at both timing periods. This might be due to the high remineralizing potential of ESP solution. The calcium and phosphorus ions can raise the hydroxyl-apatite saturation level which could be influenced by the concentration of the calcium existing in the surrounding environment. The higher the calcium and phosphorus concentrations, the higher the hydroxyl-apatite saturation level. This elevated calcium and phosphorus concentrations could result in a rapid precipitation of these ions within the bleached enamel porosities which in turns might affect the bonding results (Asmawati 2017). 
Finally, one must admit that the effect of the investigated remineralizing agents after enamel bleaching on the physical properties of resin composite restorations remains controversial till this day.

\section{Conclusions}

Regarding the limitations of the current in vitro study, the following could be concluded: ESP solution has a positive significant effect on the SBS of resin composite restorations to bleached enamel surface. ESP solution represents a powerful remineralizing agent that can successfully restore the quality of the bleached enamel surface. Delay of the bonding procedure and restoration of the bleached teeth using resin composite restorations is highly advised for better bond strength.

\section{Abbreviations}

ESP: Eggshell powder; SBS: Shear bond strength; CESP: Chicken eggshell powder; TEGDMA: Triethylene glycol dimethacrylate; UDMA: Urethane dimethacrylate; Bis-GMA: Bis-Phenol-A glycidyl-methacrylate.; LED: Light-emitting diode; CCP-ACP: Casein phospho-peptide-amorphous calcium phosphate.

\section{Acknowledgements}

Not applicable.

\section{Authors' contributions}

LM developed the original idea, main conception and constructed the study design. LM executed the study methodology and conducted the mechanical tests of the study, interpreted the results, participated in writing of the manuscript, and revised the final presented manuscript. SN was responsible for teeth preparation and manuscript writing. All authors read and approved the final manuscript.

\section{Funding}

Not applicable.

\section{Availability of data and materials}

The authors declare that the data supporting the findings of this study are available within the article.

\section{Declarations}

Ethics approval and consent to participate

Not applicable.

\section{Consent for publication}

Not applicable.

\section{Competing interests}

The authors declare that they have no competing interests.

Received: 30 October 2021 Accepted: 5 December 2021

Published online: 15 December 2021

\section{References}

Asmawati A (2017) Identification of inorganic compounds in eggshell as a dental remineralization material. J Dentomaxillofac Sci 2:168-171

Attia RM, Kamel MM (2019) Changes in surface roughness of bleached enamel by using different remineralizing agents. Tanta Dent J 13:179-186

Borges AB, Bodriques JR, Borges ALS, Marsilio AL (2007) The influence of bleaching agents on enamel bond strength of a composite resin according to the storage time. Rev Odontol UNESP 36(1):77-83
Bulucu B, Ozsezer E (2007) Influence of light curing units on dentin bond strength after bleaching. J Adhes Dent 9:183-187

Cheng YL, Musonda J, Cheng H, Attin T, Zheng M, Hao YU (2019) Effect of surface removal following bleaching on the bond strength of enamel. BMC Oral Health 19(50):1-6

Chuang SF, Chen HP, Chang CH, Liu JK (2009) Effect of fluoridated carbamide peroxide gels on enamel micro tensile bond strength. Eur J Oral Sci. 117:435-41

Cura M, Fuentes MV, Ceballos L (2015) Effect of low concentration bleaching products on enamel bond strength at different elapsed times after bleaching treatment. Dent Mater 34:203-210

Dishman MV, Covey DA, Baughan LW (1994) The effects of peroxide bleaching on composite to enamel bond strength. Dent Mater 10:33-36

Dutra AC, Albuquerque RD, Morgan LF, Perwira GM, Nunes E, Horta MC, Silveira FF (2017) Effect of bleaching on enamel surface of bovine teeth: an in vitro study. J Clin Exp Dent 9(1):46-50

Feroz S, Moeen F, Haq SN (2017) Protective effect of chicken eggshell powder solution (CESP) on artificially induced dental erosion: an in vitro atomic force microscope study. Int J Dent Sci Res 5(3):49-55

Guler E, Gonulol N, Ozyilmazo Y, Yucel AC (2013) Effect of sodium ascorbate on the bond strength of silorane and methacrylate composites after vital bleaching. Braz Oral Res 27:299-304

Haghgoo R, Mehran M, Ahmadand M, Ahmadvand MJ (2016) Remineralization effect of eggshell versus nano-hydroxyapatite on caries-like lesions in permanent teeth (In vitro). J Int Oral Health 8(4):435-439

Hussain M, Wang Y (2010) Influence of prolonged light-curing time on the shear bond strength of resin to bleached enamel. Oper Dent 35:672-681

Khoroushi M, Ghazalgoo A (2013) Effect of desensitizer application on shear bond strength of composite resin to bleached enamel. Ind J Dent Res 24(1):87-92

Kutuk ZB, Ergin E, Cakir FY, Gurgans S (2018) Effects of in-office bleaching agent combined with different desensitizing agents on enamel. J Appl Oral Sci 27:1-10

Lago AND, Garone-Netto N (2013) Microtensile bond strength of enamel after bleaching. Ind J Dent Res 24:104-109

Mobarak EH, Ali N, Daifalla LE (2015) Microshear bond strength of adhesives to enamel remineralized using casein phosphopeptide agents. Oper Dent 40:180-188

Mony B, Ebenzar AVR, Ghani MF, Narayanan A, Anand S, Mohan AJ (2015) Effect of chicken eggshell powder solution on early enamel carious lesions: an in vitro study preliminary Study. J Clin Dent Res 9(3):30-32

Moosavi H, Mohammadipour HS, Ghavamnasiri M, Alizadeh S (2015) Effect of bleaching and thermocycling on resin-enamel bond strength. Int J Biomater, 1-6

Moule CA, Angelis F, Kim GH, Le S, Malipatil S, Foo MS et al (2007) Resin bonding using an all-etch or self-etch adhesive to enamel after carbamide peroxide and/or CPP-ACP treatment. Aust Dent J 52:133-137

Shen P, Manton DJ, Cochrane NJ, Walker GD, Yuan Y, Reynolds C et al (2011) Effect of added calcium phosphate on enamel remineralization by fluoride in a randomized controlled in situ trial. J Dent 39:518-525

Shinahara MS, Peris AR, Rodrigues JA, Pj-menta LA, Ambrosano GM (2004) The effect of non-vital bleaching on the shear bond strength of composite resin using three adhesive systems. J Adhes Dent 6:205-209

Torneck CD, Titley KC, Smith DC, Adibfar A (1991) Effect of water leaching on the adhesion of composite resin to bleached and unbleached bovine enamel. J Endod 17:156-160

Torneck CD, Titley KC, Smith DC, Adibfar A (1990) The influence of time of hydrogen peroxide exposure on the adhesion of composite resin to bleached bovine enamel. J Endod 16:123-128

Van der Vyver PJ, Lewis SB, Marais JT (1997) The effect of bleaching agent on composite/enamel bonding. J Dent Assoc S Africa 52:601-603

Vidhya S, Srinivasulu S, Sujatha M, Mahalaxmi S (2011) Effect of grape seed extract on the bond strength of bleached enamel. Oper Dent 36:433-438

White DJ, Duschner H, Pioch T (2008) Effect of bleaching treatments on microleakage of class 1 restorations. J Clin Dent 19:33-36

Yu H, Zhang C, Cheng S, Cheng H (2015) Effect of bleaching agents on dental restorative materials: a review of literature and recommendations to dental practitioners and researchers. J Dent Sci. 10:345-51 


\section{Publisher's Note}

Springer Nature remains neutral with regard to jurisdictional claims in published maps and institutional affiliations. 